\title{
Research on Joint Design of New Type Fabricated Concrete Frame Structure
}

\author{
Wanlai Zhang ${ }^{1 *}$, Yue Tian ${ }^{1}$ and Yihang Zhang ${ }^{2}$ \\ ${ }^{1}$ Civil Engineering Department, Shenyang Urban Construction University, Shenyang, Liaoning Province, 110167, China \\ ${ }^{2}$ Fuxin Thermal Housing Development Co., Ltd., Fuxin, Liaoning Province, 123000, China
}

\begin{abstract}
Prefabricated structure is an important way to realize the industrialization of architecture. With its fast construction speed and high economic benefits, it has developed rapidly. This paper introduces the research status of prefabricated structure node at home. The way of beam-column connection of prefabricated concrete frame structure has hindered the progress of prefabricated concrete frame structure to some extent. This paper explores the joints of a new type of fabricated concrete frame structure. By referring to the connection method of steel structure joints, the connection complexity of beam reinforced bars is reduced to a great extent.
\end{abstract}

\section{Introduction}

Since 2011, when the State Council clearly put forward the policy of "actively promoting the industrialization of construction", the country has repeatedly issued intensive policies to promote the industrialization of construction. Under the high attention of the party central committee and the State Council, the development of China's construction industry has been comprehensively adjusted, transformed and upgraded, and started to develop in the direction of green, industrialization and information technology[1].The new type of construction industrialization focusing on the development of prefabricated buildings has been valued.

Prefabricated buildings are parts that are mass-produced in a factory according to a uniform standard. Construction by the method of site assembly obviously reduces the site wet operation, and at the same time reduces noise and pollution in the city, which making production more efficient. In recent years, the Chinese government has always been very positive about prefabricated buildings and has given strong support. But in terms of the field assembly site construction, the previous construction method is relatively rough, and precast concrete is too heavy. Due to the heavy weight of components, alignment and installation accuracy is difficult to meet the standard code of prefabricated building construction. So the construction efficiency is not good.

\subsection{The development of fabricated reinforced concrete frame structure}

For the general conventional multi-storey building, frame is main according to the previous structural scheme. But the frame structure of assembly type has the following disadvantages: (1) steel structure is very suitable for assembly type, but expensive to make;(2) the number of concrete frame need is not much, so the number of batch production is small, manufacturers profit is very low; (3) Construction has a very strict standard, nodes are large in size and weight. It's hard to get the right fit. Until now, there have been a few assembly-frame structures in which the steel bars are difficult to place. This is a great obstacle to the progress of the construction [2].

\section{Put forward the plan of new assembly frame node and explore the feasibility}

Prefabricated concrete frames are prefabricated and cast in - place. The node prefabrication method is the node prefabricated with complicated force and numerous joints of steel. to ensure the quality of the joints, we need to place steel bars in all directions in place at the same time, so construction is difficult. Also, a frame beam should have two post-pouring connections. A pillar should also be connected by two post-pouring places. More post-pouring nodes increase the difficulty of construction. Spot casting of nodes is prefabricated beam and column components, leaving nodes to be cast after construction site [3]. The advantage is that the number of post-cast node is reduced, while the core area is reinforced intensively, which makes alignment difficult. This paper studies a new connection method to improve the fault-tolerant rate of longitudinal stress reinforcement when the joints are cast-in-place.

The advantages of steel structure buildings for assembly production and construction outweigh the disadvantages. Light weight and connection convenient and accurate, but the disadvantage is easy to lose stability. 
But for concrete frame joint, there is the problem of steel alignment and force transfer. Through the device of connecting with longitudinal stress bars, the method of joint connection of steel structure is applied to concrete structure, and the feasibility is tested.

From the distribution of the stress reinforcement in the general concrete members, the reinforcement of the beam can be found is mainly concentrated on the upper and lower part of the beam section. Like the distribution of the stress flange of the member in the steel structure. But the steel column and girder flanges are continuous. Steel structural members are connected by plates and bolts. Concrete components weigh more than steel for the same type of building. The pouring node will transfer the load effect caused by dead weight. Steel is not stable due to their thinness. But when thin steel joints are wrapped in concrete points. These nodes have a firm binding on the nodal plate, which greatly enhances the bearing capacity of the nodal plate.

Therefore, it can be preliminarily determined that the end of the stressed steel bar of the beam will be welded to the steel plate, drilling holes in the steel plate. The alignment connection between steel bars is converted into a bolt connection between two steel plates. The fault tolerance of the node can be enhanced by using the bolt holes with round holes.

\section{Research on basic performance test of new type fabricated concrete frame joints}

\subsection{Assembled wet connected concrete frame joints}

Prefabricated wet joint, also known as assembled integral joint. It refers to the way in which prefabricated beams, columns, or t-shapedcomponents are connected at the junction using steel bars at the junction of prefabricated components by post-pouring. In this case, the post-pouring place is mainly located at the beam-column node or the middle of the girder span. Now, most of the connections that are used and explored are at the beam-column joints, It is generally constructed in such a way that the precast column is not poured concrete at the joint, and the precast beam ends are reserved with steel bars, and the anchorageor sleeve connection is used at the joint of the beam and column to ensure the stable connection of the longitudinal reinforcement of the upper and lower part of the beam. Generally, the precast column is not poured concrete at the node, and the precast beam end is reserved with steel bar at the beam column joint [4]. At the point, the method of anchoring or sleeve connection is used to ensure the stable connection of the upper and lower longitudinal bars of the beam. After the liting of prefabricated components, the concrete pouring operation is carried out to form the structural system.

\subsubsection{Assembly integral node with keyway}

The lower longitudinal rebar of the precast prestressed concrete beam is connected by lapping in the keyway at the beam end, and u-shaped steel is arranged in the keyway, and then concrete is poured to form the beam-column node, which can realize strength butt joint. Repeated tests show that cracking and crushing of concrete mainly lies in the keyway, the hysteretic curve of beam-column joints is full, and the energy consumption is low. This kind of frame structure is an ideal energy consumption mechanism of beam hinge.

\subsubsection{Assembly integral node without keyway}

The feature of assembling integral beam-column joints is that the connecting steel bar at the bottom of the beam end of the prefabricated beam is a closed $\mathrm{u}$-shaped prestressed steel strand, and there are three test specimens at its middle node and side node respectively. It studies the mechanical performance of the assembled integral beam-column joint when there is a connecting bar at the bottom of the beam end. The results show that when there is a $\mathrm{u}$-shaped closed prestressed steel strand and additional connecting bar at the beam end, the performance of the joint is the same as that of the cast-in-place joint.

\subsubsection{Other assembly integral node}

Other assembly integral joints have three aspects: special materials, structure and new design concept. Special materials mainly include ECC of recycled concrete used as post-pouring material; The special structure includes high-strength steel bar at the joint and post-pouring concrete. The new design concept is to change the transmission channel at the node.

\subsection{Assembled dry connected concrete frame joints}

Fabricated dry connection concrete frame joints mean that the joints are embedded in the components without pouring concrete, and the joints are jointed by means of prestressed reinforcement. The obvious difference between the dry connection and the wet connection is that in the wet connection frame, the plastic deformation should occur outside the connection and the connection should be elastic. As for the dry connection frame, the deformation occurs at the connection, and the beam and column deformation is within the elastic range. Therefore, the damage degree of the prefabricated components is small, which is easy to repair and replace after the earthquake.

\subsubsection{Precast concrete prestressed joint}

The foundation of prestressing joint of prestressing concrete is non-prestressing frame joint [5]. The main research now is post-tensioning prestressed connection. Benefits of prestressing prefabricated joints are fast 
construction speed, high production efficiency and so on. In addition, the structure is easily restored by the spring back of the prestressed tendon, and the degree of deformation is low.

\subsubsection{Fabricated concrete welded joint.}

The assembled concrete welding joint is a connection method of welding the roof, bottom plate and side plate of the frame beam in the span. By comparing the welding of 5 nodes with the cast-in-place node, the energy dissipation and stiffness of the welded node can be obtained. The bearing capacity is similar to that of the cast-in-place node. The bearing capacity interval of the node without side plate is large and the deformation is obvious.

\section{Future research direction and prospect of new type fabricated concrete frame structure joints.}

\subsection{Strengthen the research of new node}

The creation of new connections and the exploration of their performance can drive the progress of fabricated structures, such as the exploration of ductile nodes. This node has been able to meet most of the lateral displacement to dissipate energy, the design does not require the precast component to have strict ductility, if the node can be constructed scientifically, the component can be replaced after the earthquake, and the repair is more convenient and efficient than the cast-in-place structure[6].

\subsection{Application of seismic isolation technology and energy dissipation technology.}

The application of seismic isolation technology and energy dissipation technology in the assembled concrete frame structure can eliminate the deficiency of its seismic performance and enhance its seismic performance [7][8]. At the same time, the skeleton curve restorative force model and hysteretic characteristics of the assembled concrete frame structure with energy dissipation absorber should be studied more thoroughly.

\section{Conclusion}

To sum up, the reason why the strain at the top and bottom of the long side of the joint plate is obviously larger than that of the stressed steel bar is that the bolts between the two joint plates do not form a friction-type connection. Therefore, it can be preliminarily considered that when the joint bolt passes the friction type connection, the deformation between the connecting plate and letty is small and the force transmission can be more efficient. In the case of unilateral loading, the strain increment on the opposite side and the nodal plate is less than that on the side. The joint has no high standard for whether the steel bar is in place or not, high fault tolerance rate, in line with the general force transmission needs, and the requirements for bolt hole placement are not so strict. It can be used in beam with normal section with small bending moment.

\section{References}

1. Xiaoming Li. (2011) Development and Application of Key Technologies of Fabricated Concrete Structure in Foreign Countries J. Housing Industry, 6: 16-18.

2. Taichang Gu. (2014) The Current Situation of Prefabricated Buildings at Home and Abroad J Standardization of Engineering Construction, 8: 48-51.

3. Jianguo Cai, Feng Jian. Zan Wang. (2009) Seismic Performance of Precast Prestressed Concrete Assembly Integral Frame J. Journal of Sun Yat-Sen University (natural science edition), 48 (2): 136-140.

4. Zhi Dong. (2017) Study on Seismic Behavior of Prefabricated Beam-column Connection Joints with Anchor Reinforcement at Beam End and Bottom D. Nanjing: Southeast University.

5. Bin Zhao, Xilin Lv, Lizhen Liu. (2005) Experimental Study on Seismic Behavior of Beams and Columns of Fully Fabricated Precast Concrete Structures J. Earthquake Engineering and Engineering Vibration, 25 (1): 81-87.

6. Gang Wu, De Chengfeng. (2018) Research on Basic Performance of Fabricated Concrete Frame Joints J. Journal of Architectural Structure, 39 (02): 1-16.

7. Xiaoyan Yv, Huajiang. (2019) Research on Node Design of New Type Fabricated Concrete Frame Structure J. Shandong Industrial Technology (07): $111+100$.

8. Feifei Liu, Dehu Yv, Jigang Zhang. (2015) Design and Analysis of New Joints of Fabricated Concrete Frame Structure J. Journal of Qingdao University of Technology, 36(01): 118-124. 